\title{
Multi-Energy Calibration: A Practical Method for Determination of Macro and Micro Nutrients in Meat by ICP OES
}

\author{
Julymar M. Higuera, ${ }^{\oplus a, b}$ Ana Beatriz S. Silva ${ }^{\oplus a, b}$ and Ana Rita A. Nogueira ${ }^{\circledR *, a}$ \\ ${ }^{a}$ Embrapa Pecuária Sudeste, CP 339, 13560-970 São Carlos-SP, Brazil \\ ${ }^{b}$ Grupo de Análise Instrumental Aplicada, Departamento de Química, \\ Universidade Federal de São Carlos, CP 676, 13565-905 São Carlos-SP, Brazil
}

\begin{abstract}
The multi-energy calibration (MEC) was evaluated for the determination of $\mathrm{Ca}, \mathrm{Cu}, \mathrm{Fe}, \mathrm{K}, \mathrm{Mg}$, $\mathrm{Na}, \mathrm{P}, \mathrm{S}$, and $\mathrm{Zn}$ in meat samples by inductively coupled plasma optical spectrometry (ICP OES). This calibration method consists of using only two calibration standards and several atomic and ionic emission wavelengths with different sensitivities to determine the analyte concentration in the sample. Both calibration mixtures are prepared using the same amount of sample, which contributes to minimize matrix effects. The accuracy was evaluated using two certified reference materials, bovine liver (SRM 1577c) and bovine muscle (SRM 8414), with recoveries within 87-107\% range. The method was applied for the determination of the analytes in meats of chicken, sheep loin, sheep carcass and bovine, and prove to be usable in samples with different characteristics.
\end{abstract}

Keywords: calibration strategies, multi-energy, matrix effect, ICP OES

\section{Introduction}

Given the high levels of meat consumption, the quantification of toxic and essential elements in this food is required to evaluate the quality and its nutritional value, in order to estimate its effects on human health. ${ }^{1}$ The mineral content in meat varies, depending on factors such as diet, environmental conditions, cut and breed of the animal. ${ }^{2-4}$

Meat is a food rich in minerals such as $\mathrm{Ca}, \mathrm{Mg}, \mathrm{Fe}$, $\mathrm{P}$, and $\mathrm{S}$, which are found at high levels, whereas other essential minerals, such as $\mathrm{Cu}, \mathrm{Mo}, \mathrm{Se}, \mathrm{Zn}$, and $\mathrm{Co}$ are present in trace amounts. ${ }^{5}$ In the literature, numerous studies have reported different analytical methods for the quantification of these elements. Most of them comprise the use of atomic spectroscopy techniques, as inductively coupled plasma mass spectrometry (ICP-MS), inductively coupled plasma optical spectrometry (ICP OES), and graphite furnace and flame atomic absorption spectroscopy (GFAAS and FAAS) ${ }^{6-10}$ Sager et al. ${ }^{11}$ quantified macro $(\mathrm{Ca}, \mathrm{K}, \mathrm{Mg}, \mathrm{Na}$, and $\mathrm{P}$ ) and micro minerals $(\mathrm{Al}, \mathrm{Cr}, \mathrm{Cu}$, $\mathrm{Fe}, \mathrm{Mn}, \mathrm{Li}, \mathrm{Mo}, \mathrm{Ni}, \mathrm{Pb}, \mathrm{Rb}$, and $\mathrm{Zn}$ ) in chicken meat using ICP OES and ICP-MS with indium as an internal standard. Djinovic-Stojanovic et al. ${ }^{12}$ used the same analytical techniques and evaluated different internal standards, $\mathrm{Li}$,

\footnotetext{
*e-mail: ana.nogueira@embrapa.br
}

$\mathrm{Bi}, \mathrm{Ga}, \mathrm{Ln}, \mathrm{Tb}$, and $\mathrm{Y}$ for $\mathrm{Zn}$ and $\mathrm{Mg}$ determination in meat and meat products of the Serbian market.

As a general rule, when the analysis is performed by these spectroscopic techniques, external standard calibration is employed. Although it is relatively simple, important issues should be considered, such the similarity of the standard solutions with the sample matrix, to obtain reliable results and to reduce matrix effects, but achieving that matrix correspondence is not an easy task to perform. Internal standard calibration is one of the most commonly used strategies since it helps to minimize the matrix effects, reducing possible interferences. ${ }^{4}$ Another conventional method is the standard additions that gives precise results, but with an extended time of analysis and higher sample consumption. ${ }^{13}$

The multi-energy calibration (MEC), first described by Virgilio et al.,${ }^{14}$ consists of measuring different signals of an analyte at various wavelengths. In this situation, the analyte concentration is kept constant, and the transition energies are measured for calibration. This method employs only two solutions: solution 1 (S1) which is composed of $50 \%\left(\mathrm{v} \mathrm{v}^{-1}\right)$ of sample and $50 \%\left(\mathrm{v} \mathrm{v} \mathrm{v}^{-1}\right)$ of standard solution containing the analytes, and solution 2 (S2), composed of $50 \%\left(\mathrm{v} \mathrm{v}^{-1}\right)$ of sample and 50\% $\left(\mathrm{v} \mathrm{v}^{-1}\right)$ of blank solution. For this method, the use of a 1:1 ratio is simpler; however, other dilution factors may be used. Then, various wavelengths are 
selected, and the solutions 1 and 2 are analyzed individually. This calibration strategy was applied to complex liquid samples such as green tea, cola, cough medicine, soy sauce and red wine for the determination of $\mathrm{Mn}, \mathrm{Cu}$, and $\mathrm{Cr}$ by ICP OES. ${ }^{14}$ Machado et al. ${ }^{15}$ used the MEC to determine the contaminants $\mathrm{As}, \mathrm{Ba}, \mathrm{Cd}, \mathrm{Cr}$, and $\mathrm{Pb}$ in inorganic fertilizer by microwave induced optical emission spectrometry (MIP OES). Babos et al. ${ }^{16}$ employed MEC for the determination of $\mathrm{Ca}, \mathrm{Cu}, \mathrm{Fe}, \mathrm{Mn}$ and $\mathrm{Zn}$ in solid samples of bovine mineral supplements using laser-induced plasma atomic emission spectroscopy (LIBS).

The goal of this work is to investigate the applicability of the MEC as a potential calibration strategy for the quantification of $\mathrm{Ca}, \mathrm{Cu}, \mathrm{Fe}, \mathrm{K}, \mathrm{Mg}, \mathrm{Na}, \mathrm{P}, \mathrm{S}$ and $\mathrm{Zn}$ in chicken, bovine and sheep meat samples by ICP OES after microwave-assisted digestion, considering the diversity of matrix characteristics of this kind of sample.

\section{Experimental}

Instrumentation

An ICP OES (Agilent Technologies, Model 5110, Synchronous Vertical Dual View, Mulgrave, Australia) was used for $\mathrm{Ca}, \mathrm{Cu}, \mathrm{Fe}, \mathrm{K}, \mathrm{Mg}, \mathrm{Na}, \mathrm{P}, \mathrm{S}$, and $\mathrm{Zn}$ determination. The ICP OES operational parameters are shown in Table 1. Argon with purity of $99.999 \%$ (White Martins-Praxair, Sartãozinho, SP, Brazil) was used for plasma generation, nebulization and as auxiliary gas. All samples were digested by microwave-assisted digestion in an Ethos 1 system (Milestone, Sorisole, Italy).

\section{Reagents, standard solutions, and samples}

All solutions were prepared using deionized water (resistivity $>18.2 \mathrm{M} \Omega \mathrm{cm}$ ) obtained from a Milli-Q water purification system (Millipore, Bedford, MA, USA). The laboratory material used for the preparation of the solutions were washed with soap and distilled water, and then $24 \mathrm{~h}$ submerged in a $10 \%$ concentration $\left(\mathrm{v} \mathrm{v}^{-1}\right)$ of $\mathrm{HNO}_{3}$ cleaning solution and washed with deionized water before use. Nitric acid (Synth, Diadema, SP, Brazil) was previously purified using a subboiling acid distiller (Model BSB-939-IR, Distillacid, Berghof, Germany) and, together with $30 \% \mathrm{~m} \mathrm{~m}^{-1}$ of $\mathrm{H}_{2} \mathrm{O}_{2}$ (Sigma Aldrich, Darmstadt, Germany), was used to digest the meat samples and the certified reference materials. Standard solutions were prepared by diluting a $1000 \mathrm{mg} \mathrm{L}^{-1}$ stock solution of $\mathrm{Ca}, \mathrm{Cu}, \mathrm{Fe}, \mathrm{K}, \mathrm{Mg}, \mathrm{Na}, \mathrm{P}, \mathrm{S}$ and $\mathrm{Zn}$ (Fluka, Buchs, St. Gallen, Switzerland) to obtain the analytical calibration solutions for the external standard calibration (EC), the internal standard calibration (IS),
Table 1. Instrumental parameters and operating conditions for analyte determinations by ICP OES

\begin{tabular}{|c|c|}
\hline Instrumental parameter & Operating condition \\
\hline Radio frequency applied power / $\mathrm{kW}$ & 1.2 \\
\hline Plasma gas flow / $\left(\mathrm{L} \mathrm{min}^{-1}\right)$ & 12.0 \\
\hline Auxiliary gas flow / $\left(\mathrm{L} \mathrm{min}^{-1}\right)$ & 1.0 \\
\hline Nebulization gas flow / $\left(\mathrm{L} \mathrm{min}^{-1}\right)$ & 0.7 \\
\hline Peristaltic pump speed / rpm & 12 \\
\hline View & $\begin{array}{c}\text { axial }(\mathrm{Cu}, \mathrm{Fe}, \mathrm{P}, \mathrm{S}, \mathrm{Zn}) \text { and radial } \\
(\mathrm{Ca}, \mathrm{K}, \mathrm{Mg}, \mathrm{Na})\end{array}$ \\
\hline Stabilization time / s & 15 \\
\hline Integration time / s & 3 \\
\hline Nebulizer & concentric \\
\hline Nebulization chamber & cyclonic, double step \\
\hline Analyte & Wavelength / nm \\
\hline $\mathrm{Ca}$ & $\begin{array}{l}\text { 183.944; 315.887; } 317.933 ; \\
\text { 318.127; } 370.602 ; 373.690 ; \\
\text { 383.034; 386.409; 404.272; } \\
\text { 407.865; 422.673; 430.253; } \\
\text { 431.865; 443.496; 445.478; } \\
612.222 ; 616.217 \text { and } 643.907\end{array}$ \\
\hline $\mathrm{Cu}$ & $\begin{array}{c}199.970 ; 217.895 ; 218.963 ; \\
219.227 ; 219.959 ; 222.778 ; \\
223.009 ; 224.427 \text { and } 224.700\end{array}$ \\
\hline $\mathrm{Fe}$ & $\begin{array}{c}234.350 ; 238.204 ; 239.563 \\
240,489 ; 258.588 ; 259.940 \\
260.709 ; 261.187 ; 261.382 ; \\
273.358 ; 370.792 \text { and } 373.13\end{array}$ \\
\hline K & $\begin{array}{c}321.715 ; 344.637 ; 344.738 ; \\
404.414 ; 404.721 ; 633.178 ; \\
662.367 ; 693.527 ; 693.876 ; \\
\quad 766.491 \text { and } 769.897\end{array}$ \\
\hline $\mathrm{Mg}$ & $\begin{array}{c}202.582 ; 277.983 ; 278.142 ; \\
279.078 ; 279.553 ; 279.800 ; \\
280.270 ; 285.213 ; 293.651 ; \\
294.199 ; 383.230 \text { and } 383.829\end{array}$ \\
\hline $\mathrm{Na}$ & $\begin{array}{c}285.281 ; 330.237 ; 330.298 ; \\
545.418 ; 547.766 ; 566.923 ; \\
568.821 ; 591.435 ; 614.153 ; \\
\quad 615.423 \text { and } 640.211\end{array}$ \\
\hline $\mathrm{P}$ & $\begin{array}{c}177.434 ; 178.222 ; 178.703 ; \\
184.654 ; 185.057 ; 185.827 ; \\
185.878 ; 203.347 ; 213.547 ; \\
213.618 ; 214.914 ; 215.407 ; \\
\quad 253.561 \text { and } 255.326 \\
\end{array}$ \\
\hline S & $\begin{array}{c}\text { 178.165; } 180.669 ; 181.972 ; \\
182.562 ; 189.965 ; 191.406 ; \\
178.165 ; 180.669 ; 181.972 ; \\
182.562 ; 189.965 \text { and } 191.406\end{array}$ \\
\hline $\mathrm{Zn}$ & $\begin{array}{c}\text { 202.548; 206.200; 207.908; } \\
\text { 208.733; 209.693; 209.994; } \\
210.442 ; 218.57 ; 280.086 ; 328.233 ; \\
330.258 ; 334.502 ; 334.557 \text { and } \\
472.215\end{array}$ \\
\hline $\mathrm{Y}$ & 360.074 (internal standard) \\
\hline
\end{tabular}


the standard additions (SA), and the MEC. Yttrium in the concentration of $5 \mathrm{mg} \mathrm{L}^{-1}$ was used as an internal standard in the IS calibration. The range of calibration curves for EC was $0.5-50 \mathrm{mg} \mathrm{L}^{-1}$ for each evaluated analyte.

Chicken, sheep loin, sheep carcass, and bovine meat samples were obtained in the local market (São Carlos, SP, Brazil). The method validation was performed by using the certified reference materials (CRM) bovine liver (SRM 1577c) and beef muscle (SRM 8414) (National Institute of Standards and Technology (NIST), Gaithersburg, MD, USA).

\section{Sample preparation}

The meat samples were lyophilized (Model EC, MicroModulyo, New York, NY, USA), ground in a cryogenic mill (MA775, Marconi, Piracicaba, SP, Brazil), and homogenized. For the microwave digestion, approximately $100 \mathrm{mg}$ of sample was weighed, and $3.0 \mathrm{~mL}$ of concentrated $\mathrm{HNO}_{3}, 5 \mathrm{~mL}$ of water, along with $2.0 \mathrm{~mL}$ of $30 \%\left(\mathrm{~m} \mathrm{~m}^{-1}\right)$ of $\mathrm{H}_{2} \mathrm{O}_{2}$ were added to the samples. The microwave heating program was applied in three steps: 15 min to reach $120^{\circ} \mathrm{C}, 20 \mathrm{~min}$ to reach $180{ }^{\circ} \mathrm{C}$ and a standby time of $20 \mathrm{~min}$ at $180{ }^{\circ} \mathrm{C}$ (both at $1300 \mathrm{~W}$ power). After cooling to room temperature, the volumes were adjusted to $30 \mathrm{~mL}$ with deionized water.

\section{MEC solutions}

As previously mentioned, two solutions were prepared for MEC procedure. The selected ratio was 1:1, the solution 1 (S1) was composed by $50 \%\left(\mathrm{v} \mathrm{v}^{-1}\right)$ of digested meat sample and $50 \%\left(\mathrm{v} \mathrm{v}^{-1}\right)$ of standard solutions containing the analytes. In this case, the analyte concentrations in standard solution $\left(\mathrm{C}^{\text {Standard }}\right)$ were chosen by an earlier unpublished study. Solution 2 (S2) was composed of 50\% $\left(\mathrm{v} \mathrm{v}^{-1}\right)$ of digested meat sample and $50 \%\left(\mathrm{v} \mathrm{v}^{-1}\right)$ of the blank analytical solution.

\section{Results and Discussion}

The solutions for the construction of the calibration curve were prepared using a ratio of $1: 1$. The ratio was chosen to simplify the calculations of the analyte concentrations as well as to assume an intermediate concentration level between the sample and the standard. It should be emphasized that other ratios may be used, which will depend on the type of sample being analyzed. For example, samples with higher content of dissolved solids may require a higher dilution factor to improve the analytical response and not to clog in the nebulization system. ${ }^{14}$
The calibration curve was constructed considering the signals of $\mathrm{S} 1$ on the $x$-axis, while the $\mathrm{S} 2$ on the $y$-axis, thus generating a single point on the calibration curve. For each analyte, the wavelengths that had the highest sensitivity were selected, and the signals in each solution were measured. The first aspect related to the MEC is the easy detection of the emission lines that present spectral interferences. For this identification, it is only necessary to observe the points that stand outside the curve (linear model). During the calibration process, these lines are merely discarded..$^{14-16}$

After the analysis of the wavelengths for each analyte, the emission lines were selected, resulting in 18 emission lines for $\mathrm{Ca}, 9$ emission lines for $\mathrm{Cu}, 12$ emission lines for $\mathrm{Fe}, 11$ emission lines for $\mathrm{K}, 12$ emission lines for $\mathrm{Mg}, 11$ emission lines for $\mathrm{Na}, 14$ emission lines for $\mathrm{P}$, 12 emission lines for S, and 14 emission lines for $\mathrm{Zn}$. Each selected emission line represents a point on the calibration curve, as was previously mentioned.

The obtained calibration curve for $\mathrm{Cu}$ in bovine liver (SRM 1577c) is shown in Figure 1.

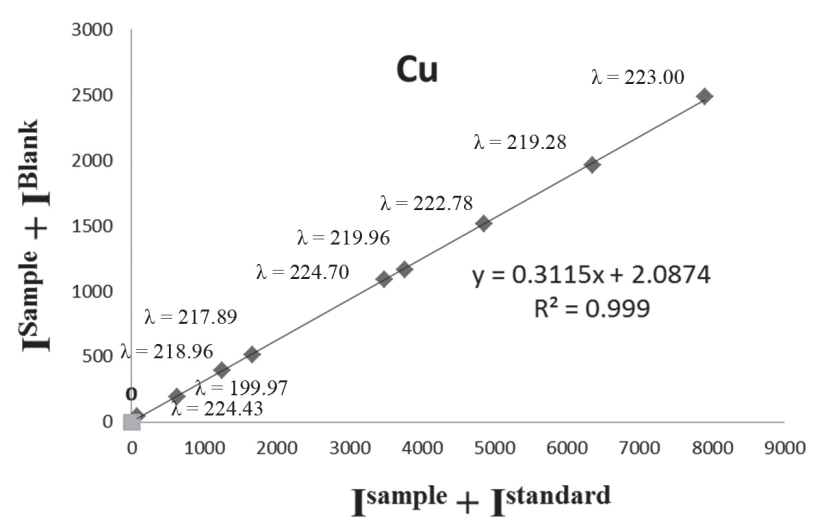

Figure 1. MEC curve used for the Cu determination by ICP OES in bovine liver (SRM 1577c).

According to Virgilio et al.,${ }^{14}$ to choose the appropriate concentration of the standard, the signal ratio of the solutions S1 and S2 must be measured, and the desirable range should be between $10 \geq(\mathrm{S} 1 / \mathrm{S} 2) \geq 1.1$. This condition corresponds to an inclination between 0.1 and 0.9 and implies that the extremes would be avoided. The highlighted numbers presented in Table 2 represent the conditions used in all following MEC analyses. It should be noted that the slope in the $\mathrm{Cu}$ calibration curve for the CRM bovine muscle was around 0.01 . The low amount of $\mathrm{Cu}$ in the CRM sample can explain this obtained low value, which was below the limit of detection (LOD) of the method, as confirmed further. The angular coefficients of the other evaluated analytes in the CRM 1577c (bovine liver) were between 0.19 and 0.39 . 
Table 2. MEC parameters of $\mathrm{Ca}, \mathrm{Cu}, \mathrm{Fe}, \mathrm{Mg}, \mathrm{P}, \mathrm{S}$, and $\mathrm{Zn}$ determination in meat certified reference materials by ICP OES

\begin{tabular}{|c|c|c|c|c|c|c|c|}
\hline \multirow{2}{*}{ Analyte } & \multirow{2}{*}{$\begin{array}{c}\text { Parameter } \\
\text { slope }\end{array}$} & \multicolumn{3}{|c|}{ Bovine liver ${ }^{\mathrm{a}} /\left(\mathrm{mg} \mathrm{L}^{-1}\right)$} & \multicolumn{3}{|c|}{ Bovine muscle $\mathrm{e}^{\mathrm{b}} /\left(\mathrm{mg} \mathrm{L}^{-1}\right)$} \\
\hline & & 0.310 & 0.474 & 0.674 & 0.319 & 0.471 & 0.677 \\
\hline \multirow{3}{*}{$\mathrm{Ca}$} & $\mathrm{C}^{\mathrm{Std}}$ & 1 & 0.5 & 0.2 & 1 & 0.5 & 0.2 \\
\hline & $C^{\text {analyte }}$ & 0.445 & 0.45 & 0.413 & 0.448 & 0.446 & 0.420 \\
\hline & $\mathrm{C}^{\text {certificated }}$ & & 0.436 & & & 0.483 & \\
\hline \multirow{4}{*}{$\mathrm{Cu}$} & slope & 0.310 & 0.468 & 0.683 & 0.012 & 0.018 & 0.051 \\
\hline & $\mathrm{C}^{\mathrm{Std}}$ & 2 & 1 & 0.4 & 2 & 1 & 0.4 \\
\hline & $C^{\text {analyte }}$ & 0.883 & 0.879 & 0.861 & & $<0.01$ & \\
\hline & $\mathrm{C}^{\text {certificated }}$ & \multicolumn{2}{|c|}{0.920} & & & 0.009 & \\
\hline \multirow{4}{*}{$\mathrm{Fe}$} & slope & 0.388 & 0.554 & 0.754 & 0.175 & 0.295 & 0.516 \\
\hline & $\mathrm{C}^{\mathrm{Std}}$ & 1 & 0.50 & 0.20 & 1 & 0.5 & 0.2 \\
\hline & $\mathrm{C}^{\text {analyte }}$ & 0.635 & 0.500 & 0.200 & 0.212 & 0.209 & 0.210 \\
\hline & $\mathrm{C}^{\text {certificated }}$ & & 0.660 & & & 0.237 & \\
\hline \multirow{4}{*}{ K } & slope & 0.286 & 0.355 & 0.571 & 0.337 & 0.501 & 0.715 \\
\hline & $\mathrm{C}^{\mathrm{Std}}$ & 100 & 50 & 20 & 100 & 50 & 20 \\
\hline & $\mathrm{C}^{\text {analyte }}$ & 27.817 & 27.890 & 26.625 & 50.333 & 50.171 & 50.200 \\
\hline & $\mathrm{C}^{\text {certificated }}$ & & 34.100 & & & 50.390 & \\
\hline \multirow{4}{*}{$\mathrm{Mg}$} & slope & 0.303 & 0.400 & 0.540 & 0.320 & 0.610 & 0.700 \\
\hline & $\mathrm{C}^{\mathrm{Std}}$ & 5 & 2 & 1 & 5 & 2 & 1 \\
\hline & $C^{\text {analyte }}$ & 2.174 & 1.333 & 1.174 & 2.353 & 3.128 & 2.333 \\
\hline & $\mathrm{C}^{\text {certificated }}$ & & 2.060 & & & 3.200 & \\
\hline \multirow{4}{*}{$\mathrm{Na}$} & slope & 0.190 & 0.330 & 0.552 & 0.205 & 0.392 & 0.620 \\
\hline & $\mathrm{C}^{\mathrm{Std}}$ & 30 & 15 & 6 & 20 & 10 & 4 \\
\hline & $\mathrm{C}^{\text {analyte }}$ & 7.037 & 7.395 & 7.400 & 6.684 & 6.440 & 6.527 \\
\hline & $\mathrm{C}^{\text {certificated }}$ & & 6.778 & & & 7.000 & \\
\hline \multirow{4}{*}{$P$} & slope & 0.289 & 0.443 & 0.660 & 0.215 & 0.349 & 0.574 \\
\hline & $\mathrm{C}^{\mathrm{Std}}$ & 100 & 50 & 20 & 100 & 50 & 20 \\
\hline & $C^{\text {analyte }}$ & 39.790 & 38.750 & 38.806 & 26.448 & 26.850 & 26.958 \\
\hline & $\mathrm{C}^{\text {certificated }}$ & & 39.160 & & & 27.860 & \\
\hline \multirow{4}{*}{ S } & slope & 0.165 & 0.322 & 0.531 & 0.202 & 0.318 & 0.544 \\
\hline & $\mathrm{C}^{\mathrm{Std}}$ & 100 & 50 & 20 & 100 & 50 & 20 \\
\hline & $\mathrm{C}^{\text {analyte }}$ & 19.799 & 23.727 & 22.633 & 24.908 & 23.362 & 23.86 \\
\hline & $\mathrm{C}^{\text {certificated }}$ & & 24.960 & & & 26.5 & \\
\hline \multirow{4}{*}{$\mathrm{Zn}$} & slope & 0.217 & 0.355 & 0.564 & 0.186 & 0.31 & 0.551 \\
\hline & $\mathrm{C}^{\mathrm{Std}}$ & 2 & 1 & 0,4 & 2 & 1 & 0.4 \\
\hline & $C^{\text {analyte }}$ & 0.551 & 0.549 & 0.518 & 0.457 & 0.449 & 0.492 \\
\hline & $\mathrm{C}^{\text {certificated }}$ & & 0.604 & & & 0.473 & \\
\hline
\end{tabular}

a SRM 1577c; 'SRM 841. $\mathrm{C}^{\text {Std: }}$ analyte concentration in the standard solution; $\mathrm{C}^{\text {analyte }}$ : calculated sample concentration by using MEC (equation 2); $C^{\text {certificated: }}$ CRM analyte concentration (100 mg of sample in $30 \mathrm{~mL}$ of digested final volume). The highlighted numbers represent the conditions used in all following MEC analyses.

Using the coefficient of the calibration curve (slope) and the analyte concentration added in $\mathrm{S} 1\left(\mathrm{C}^{\mathrm{Std}}\right)$, the analyte concentration $\left(\mathrm{C}^{\text {analyte }}\right)$ in the sample can be calculated according to the following equations: ${ }^{14}$

Slope $=\frac{\left(C^{\text {analyte }}\right)}{\left(C^{\text {analyte }}+C^{\text {Std }}\right)}$
Moreover, rearranging equation 1 as $\mathrm{C}^{\text {Std }}$ is known:

$$
\mathrm{C}^{\text {analyte }}=\frac{\left(\text { slope } \times \mathrm{C}^{\mathrm{Std}}\right)}{(1-\text { slope })}
$$

Different concentrations were studied for each analyte in both reference materials (bovine liver and bovine muscle) 
to evaluate how the concentration of the analyte ( $\left.\mathrm{C}^{\text {analyte }}\right)$ varies concerning the concentration of the standard solution $\left(\mathrm{C}^{\mathrm{Std}}\right)$. The $50 \mathrm{mg} \mathrm{L}^{-1}$ standard solution was used to calculate the analyte concentration of $\mathrm{P}$ in the sample. It should be noted that higher value was obtained with a solution of $20 \mathrm{mg} \mathrm{L}^{-1}$. Otherwise, when the value was corrected to the mass fraction, the recovery was lower. According to the results shown in Table 2, it can be observed that the best results (highlighted concentrations) were obtained when $\mathrm{C}^{\text {Std }}$ was at least twice or equal to the analyte concentrations in the sample, as reported by Machado et al. ${ }^{15}$

The EC, IS, and SA calibration procedures were accomplished in a comparative study. To evaluate these calibrations, we calculated the recoveries of the analytes, that are shown in Table 3. The recovery intervals were obtained in the range of $73-98.6 \%$ for the EC, $87-108 \%$ for the IS, 86-115\% for the SA and 87-107\% for the MEC.

When the external calibration was applied, the $\mathrm{Na}$ accuracy presented unsatisfactory results. $\mathrm{Na}$ can be considered as a readily ionizable element $(5.1 \mathrm{eV})$ and, according to the results, is remarkable that the high matrix effect needs to be compensated by the application of the IS or the SA calibration strategies. Also, the use of MEC for $\mathrm{Na}$ was more effective because it improves the accuracy compared to the other tested calibrations methods. In the same way, the use of MEC improved the accuracy of $\mathrm{Ca}$, $\mathrm{Mg}, \mathrm{P}, \mathrm{S}$, and $\mathrm{Zn}$ in the evaluated CRM.

Meat is as a complex organic matrix, and when digested, it presents dissolved carbon content that can provide spectral interferences, mainly for elements with the high energy of ionization. Besides, the presence of readily ionizable elements in the matrix such as $\mathrm{Na}, \mathrm{K}$, and $\mathrm{Mg}$ modifies the electrical density in the plasma, and consequently, the analyte signals can be suppressed. For this reason, calibration strategies that employ matrix matching principles such as MEC are more appropriate to overcome such interference.

The MEC accuracy, estimated using the reference materials, are shown in Table 4. The analysis of variance (ANOVA) test statistical analysis was performed, and a significant difference was observed at $95 \%$ of confidence for $\mathrm{Fe}$ and $\mathrm{Zn}$ in the bovine liver. This difference can be given by the deviation in the determined value, increasing the uncertainty. For the other analytes in both reference materials, the $t$ calculated was lower than the table to $95 \%$ confidence.

It is important to highlight that the MEC has the main advantage of simplicity in comparison to the classic calibration strategies. Since only two solutions are used, shorter preparation time is required. Likewise, it must be taken into account that applying MEC as a calibration strategy only one calibration curve needs to be prepared to calculate the slope of the line to determine the concentration of the analyte. For determining the most appropriate wavelength for calculating the concentration of the analytes, other classic calibration methods need one calibration curve for each wavelength. The MEC also has array matching capability, and therefore the matrix effects can be reduced. However, compared to the EC the measurement time of each sample is more extended because several wavelengths per analyte must be analyzed for both solutions, which can decrease the analytical frequency depending on the number of elements analyzed. Also, the MEC is prone to systematic errors during the preparation of the solutions, and the analyte must present multiple analytical lines to be able to apply this type of calibration strategy.

Table 3. Recovery of $\mathrm{Ca}, \mathrm{Cu}, \mathrm{Fe}, \mathrm{Mg}, \mathrm{K}, \mathrm{Na}, \mathrm{P}, \mathrm{S}$, and $\mathrm{Zn}$ in CRM using various calibration strategies. Mass fraction determined by ICP OES ( $\mathrm{n}=3$ )

\begin{tabular}{|c|c|c|c|c|c|c|c|c|}
\hline \multirow{2}{*}{ Analyte } & \multicolumn{4}{|c|}{ Bovine liver ${ }^{\mathrm{a}} / \%$} & \multicolumn{4}{|c|}{ Bovine muscle ${ }^{\mathrm{b}} / \%$} \\
\hline & $\mathrm{EC}$ & IS & SA & MEC & $\mathrm{EC}$ & IS & SA & MEC \\
\hline $\mathrm{Ca}$ & 98.6 & 108.0 & 104.4 & 100.2 & 79.5 & 91.3 & 94.1 & 95.2 \\
\hline $\mathrm{Cu}$ & 97.1 & 89.4 & 129.2 & 95.9 & $<\mathrm{LOD}$ & $<\mathrm{LOD}$ & $<$ LOD & $<$ LOD \\
\hline $\mathrm{Fe}$ & 92.1 & 93.2 & 98.48 & 95.6 & 84.0 & 88.0 & 93.7 & 94.2 \\
\hline $\mathrm{Mg}$ & 82.2 & 84.2 & 93.8 & 97.2 & 82.9 & 87.3 & 87.0 & 98.4 \\
\hline $\mathrm{K}$ & 92.4 & 91.3 & 96.1 & 101.9 & 85.4 & 89.2 & 86.1 & 98.0 \\
\hline $\mathrm{Na}$ & 74.1 & 88.7 & 114.6 & 107.0 & 73.1 & 88.5 & 109.3 & 102.1 \\
\hline $\mathrm{P}$ & 92.3 & 89.8 & 93.5 & 99.1 & 88.1 & 88.0 & 87.2 & 93.0 \\
\hline$S$ & 93.1 & 88.2 & 102.9 & 98.8 & 96.1 & 94.4 & 97.4 & 91.2 \\
\hline $\mathrm{Zn}$ & 84.4 & 88.1 & 88.2 & 92.7 & 79.8 & 87.2 & 93.8 & 87.4 \\
\hline
\end{tabular}

${ }^{a}$ SRM 1577c; bSRM 8414. EC: external calibration; IS: internal standard; SA: standard addition; MEC: multi-energy calibration; LOD: limit of detection $\left(\mathrm{Cu}: 3 \mathrm{mg} \mathrm{kg}^{-1}\right)$. 
Table 4. $\mathrm{Ca}, \mathrm{Cu}, \mathrm{Fe}, \mathrm{Mg}, \mathrm{K}, \mathrm{Na}, \mathrm{P}, \mathrm{S}$, and $\mathrm{Zn}$ mass fraction obtained in two CRM using MEC by ICP OES (concentration \pm standard deviation, $\mathrm{n}=3$ )

\begin{tabular}{|c|c|c|c|c|}
\hline \multirow{2}{*}{ Analyte } & \multicolumn{2}{|c|}{ Bovine liver $^{\mathrm{a}}$} & \multicolumn{2}{|c|}{ Bovine muscle $^{b}$} \\
\hline & Certificate & Determined & Certificate & Determined \\
\hline $\mathrm{Ca} /\left(\mathrm{mg} \mathrm{kg}^{-1}\right)$ & $131 \pm 10$ & $131 \pm 2$ & $145 \pm 20$ & $138 \pm 4$ \\
\hline $\mathrm{Cu} /\left(\mathrm{mg} \mathrm{kg}^{-1}\right)$ & $275.2 \pm 4.6$ & $264 \pm 53$ & $2.84 \pm 0.45$ & $<$ LOD \\
\hline $\mathrm{Fe} /\left(\mathrm{mg} \mathrm{kg}^{-1}\right)$ & $197.94 \pm 0.65$ & $189.3 \pm 2.3$ & $71.2 \pm 9.2$ & $66.8 \pm 1.3$ \\
\hline $\mathrm{Mg} /\left(\mathrm{mg} \mathrm{kg}^{-1}\right)$ & $620 \pm 42$ & $637 \pm 70$ & $960 \pm 95$ & $945 \pm 28$ \\
\hline $\mathrm{K} /\left(\% \mathrm{~m} \mathrm{~m}^{-1}\right)$ & $1.023 \pm 0.064$ & $1.042 \pm 0.041$ & $1.517 \pm 0.037$ & $1.49 \pm 0.03$ \\
\hline $\mathrm{Na} /\left(\% \mathrm{~m} \mathrm{~m}^{-1}\right)$ & $0.2033 \pm 0.0064$ & $0.218 \pm 0.002$ & $0.210 \pm 0.008$ & $0.196 \pm 0.004$ \\
\hline $\mathrm{P} /\left(\% \mathrm{~m} \mathrm{~m}^{-1}\right)$ & $1.175 \pm 0.027$ & $1.164 \pm 0.020$ & $0.836 \pm 0.045$ & $0.78 \pm 0.03$ \\
\hline $\mathrm{S} /\left(\% \mathrm{~m} \mathrm{~m}^{-1}\right)$ & $0.749 \pm 0.034$ & $0.74 \pm 0.03$ & $0.795 \pm 0.041$ & $0.725 \pm 0.021$ \\
\hline $\mathrm{Zn} /\left(\mathrm{mg} \mathrm{kg}^{-1}\right)$ & $181.1 \pm 1$ & $167.8 \pm 5.8$ & $142 \pm 14$ & $123 \pm 15$ \\
\hline
\end{tabular}

${ }^{\mathrm{a} S R M} 1577 \mathrm{c}$; ${ }^{\mathrm{Z} S R M}$ 8414. LOD: limit of detection $\left(\mathrm{Cu}: 3 \mathrm{mg} \mathrm{kg}^{-1}\right)$.

\section{Limit of detection (LOD)}

The LOD were determined according to preconized by the International Union of Pure and Applied Chemistry (IUPAC), as 3 times the equivalent concentration of blank $\left(\mathrm{LOD}=3 \mathrm{C}_{\mathrm{B}}\right)$. To calculate the LOD, we used the solution $\mathrm{S} 1$ as $25 \mathrm{~mL}$ of $1 \% \mathrm{HNO}_{3}$ plus $25 \mathrm{~mL}$ of $1 \mathrm{mg} \mathrm{L}^{-1}$ analyte standard, and $\mathrm{S} 2$ as $25 \mathrm{~mL}$ of $1 \% \mathrm{HNO}_{3}$ solution $\left(\mathrm{v} \mathrm{v}^{-1}\right)$ plus $25 \mathrm{~mL}$ of blank digestion solution, used as a sample. The blank concentration was then calculated using the MEC $(\mathrm{n}=10)$. The LOD calculated were $0.02,0.01,0.001,0.1$, $0.002,0.2,0.05,0.2$, and $0.06 \mathrm{mg} \mathrm{L}^{-1}$ for $\mathrm{Ca}, \mathrm{Cu}, \mathrm{Fe}, \mathrm{K}$, $\mathrm{Mg}, \mathrm{Na}, \mathrm{P}, \mathrm{S}$ and $\mathrm{Zn}$, respectively.

Expressing the results in mass fraction, the LODs for $\mathrm{Ca}, \mathrm{Cu}, \mathrm{Fe}, \mathrm{Mg}$, and $\mathrm{Zn}$ were found as 6, 3, 0.3, 0.7, and $19 \mathrm{mg} \mathrm{kg}^{-1}$, respectively. For K, Na, P and S, the LODs were $0.0004,0.0006,0.0001$, and $0.0006 \mathrm{~g} \mathrm{~kg}^{-1}$, respectively. The limits of quantification (LOQ) were 19, 10, 1, 2, $58 \mathrm{mg} \mathrm{kg}^{-1}$, and $0.001,0.002,0.0003$ and $0.002 \mathrm{~g} \mathrm{~kg}^{-1}$ for $\mathrm{Ca}, \mathrm{Cu}, \mathrm{Fe}$, $\mathrm{Mg}, \mathrm{Zn}$, and $\mathrm{K}, \mathrm{Na}, \mathrm{P}$ and $\mathrm{S}$, respectively.

The values obtained here are mostly comparable to those found in the literature concerning the determination of macro and micro minerals in meat. Sager et al. ${ }^{11}$ determined
$\mathrm{Ca}, \mathrm{K}, \mathrm{Mg}, \mathrm{Na}, \mathrm{P}, \mathrm{Cu}, \mathrm{Fe}$ and $\mathrm{Zn}$ in chicken meat by $\mathrm{ICP}$ OES and obtained LOD of 0.01, 0.01, 0.002, 0.005 and $0.01 \mathrm{~g} \mathrm{~kg}^{-1}$ for $\mathrm{Ca}, \mathrm{K}, \mathrm{Mg}, \mathrm{Na}$, and $\mathrm{P}$, respectively. For $\mathrm{Cu}$, $\mathrm{Fe}$, and $\mathrm{Zn}$, these values were found to be $0.20,3.7$ and $1.8 \mathrm{~g} \mathrm{~kg}^{-1}$. Vieira et al. ${ }^{17}$ determined $\mathrm{Ca}, \mathrm{Cu}, \mathrm{Fe}, \mathrm{K}, \mathrm{Mg}$, $\mathrm{Mn}, \mathrm{Na}, \mathrm{P}, \mathrm{S}$ and $\mathrm{Zn}$ in meat by ICP OES, with $2,0.5,1.5$, $1.2,0.4,0.1,5,4,4$ and $1 \mathrm{mg} \mathrm{kg}^{-1}$ of LOQ, respectively.

$\mathrm{Cu}$ and $\mathrm{Zn}$ were determined in sheep muscle by ICP OES with LOD of $0.0109 \mathrm{mg} \mathrm{kg}^{-1}$ for $\mathrm{Cu}$ and $0.0357 \mathrm{mg} \mathrm{kg}^{-1}$ for $\mathrm{Zn}$, values lower than those found in the present work. This may have occurred due to the different way of LOD determination. ${ }^{18}$

\section{Meat samples analysis}

The MEC was applied to the nutrients determination of different types of meat samples, and the results are summarized in Table 5. The assessed samples had levels of $\mathrm{Cu}$ below the LOQ of the method $\left(2.92 \mathrm{mg} \mathrm{kg}^{-1}\right)$.

Comparing the mass fraction of nutrients obtained in several types of meat with the results reported in the literature, it could be observed the similarity with the obtained results in the current work. ${ }^{2,4,12,17,19}$

Table 5. Mass fraction of $\mathrm{Ca}, \mathrm{Cu}, \mathrm{Fe}, \mathrm{Mg}, \mathrm{K}, \mathrm{Na}, \mathrm{P}, \mathrm{S}$, and $\mathrm{Zn}$ in different types of meat using $\mathrm{MEC}$ (measurement \pm standard deviation, $\mathrm{n}=3$ )

\begin{tabular}{|c|c|c|c|c|}
\hline \multirow{2}{*}{ Analyte } & \multicolumn{4}{|c|}{ Sample } \\
\hline & Chicken & Sheep loin & Sheep carcass & Bovine \\
\hline $\mathrm{Ca} /\left(\mathrm{mg} \mathrm{kg}^{-1}\right)$ & $165.9 \pm 1.5$ & $215.04 \pm 0.70$ & $18.067 \pm 1676$ & $205 \pm 15$ \\
\hline $\mathrm{Cu} /\left(\mathrm{mg} \mathrm{kg}^{-1}\right)$ & $<$ LOD & $<$ LOD & $<$ LOD & $<$ LOD \\
\hline $\mathrm{Fe} /\left(\mathrm{mg} \mathrm{kg}^{-1}\right)$ & $19.2 \pm 0.5$ & $62 \pm 1$ & $54 \pm 4$ & $48 \pm 2$ \\
\hline $\mathrm{Mg} /\left(\mathrm{mg} \mathrm{kg}^{-1}\right)$ & $899 \pm 16$ & $888 \pm 9$ & $1417 \pm 12$ & $700 \pm 28$ \\
\hline $\mathrm{K} /\left(\% \mathrm{~m} \mathrm{~m}^{-1}\right)$ & $2.8 \pm 0.5$ & $1.3 \pm 0.2$ & $0.9 \pm 0.1$ & $1.2 \pm 0.2$ \\
\hline $\mathrm{Na} /\left(\% \mathrm{~m} \mathrm{~m}^{-1}\right)$ & $0.29 \pm 0.05$ & $0.29 \pm 0.03$ & $0.42 \pm 0.07$ & $0.35 \pm 0.02$ \\
\hline $\mathrm{P} /\left(\% \mathrm{~m} \mathrm{~m}^{-1}\right)$ & $0.80 \pm 0.01$ & $0.81 \pm 0.02$ & $3.4 \pm 0.2$ & $0.60 \pm 0.03$ \\
\hline $\mathrm{S} /\left(\% \mathrm{~m} \mathrm{~m}^{-1}\right)$ & $0.71 \pm 0.01$ & $0.88 \pm 0.03$ & $0.37 \pm 0.06$ & $0.53 \pm 0.02$ \\
\hline $\mathrm{Zn} /\left(\mathrm{mg} \mathrm{kg}^{-1}\right)$ & $29.85 \pm 0.01$ & $77 \pm 1$ & $57 \pm 4$ & $121 \pm 3$ \\
\hline
\end{tabular}

LOD: limit of detection $\left(\mathrm{Cu}: 3 \mathrm{mg} \mathrm{kg}^{-1}\right)$. 


\section{Conclusions}

According to the obtained results, the MEC presents itself as a potential calibration strategy for the rapid and efficient quantification of macro and micro minerals in meat samples. This calibration strategy does not require modifications to the instrumentation nor the preparation of a wide range of standards. The recovery percentages were between 87 and $107 \%$ for the analyzed analytes. The results obtained did not present significant differences when compared to the traditional calibration procedures. Beyond being time-consuming compared to the external calibration and the requirement of multiple analytical lines of the analytes, MEC proved to be useful in complex samples, which requires matrix matching strategies to avoid analysis interference.

\section{Acknowledgments}

The authors would like to thank the Brazilian agencies Fundação de Amparo à Pesquisa do Estado de São Paulo (2018/26145-9) and the National Bank for Economic and Social Development (BNDES) for the financial support. A. R. A. N., J. M. I., and A. B. S. S. are thankful to the Conselho Nacional de Desenvolvimento Científico e Tecnológico for researchship (307639/2014-2) and fellowships (141315/2017-2, 153125/2016-0). This is a contribution of the National Institute of Advanced Analytical Science and Technology (INCTAA).

\section{References}

1. Pereira, P. M. C. C.; Vicente, A. F. R. B.; Meat Sci. 2013, 93, 586.

2. Cabrera, M. C.; Ramos, A.; Saadoun, A.; Brito, G.; Meat Sci. 2010, 84, 518.

3. Ramos, A.; Cabrera, M. C.; Saadoun, A.; Meat Sci. 2012, 91, 116.
4. Pilarczyk, R.; Biol. Trace Elem. Res. 2014, 158, 36.

5. Cabrera, M. C.; Saadoun, A.; Meat Sci. 2014, 98, 435.

6. Bou, R.; Guardiola, F.; Padró, A.; Pelfort, E.; Codony, R.; J. Anal. At. Spectrom. 2004, 19, 1361.

7. Falandysz, J.; Szymczyk-Kobrzyńska, K.; Brzostowski, A.; Zalewski, K.; Zasadowski, A.; Food Addit. Contam. 2005, 22, 141.

8. Gerber, N.; Brogioli, R.; Hattendorf, B. N.; Scheeder, M. R. L.; Animal 2009, 3, 166.

9. López-Alonso, M.; Miranda, M.; Benedito, J. L.; Pereira, V.; García-Vaquero, M.; Meat Sci. 2016, 121, 47.

10. Andrade, R. M.; Gois, J. S.; Toaldo, I. M.; Batista, D. B.; Luna, A. S.; Borges, D. L. G.; Food Anal. Methods 2017, 10, 1209.

11. Sager, M.; Lucke, A.; Ghareeb, K.; Allymehr, M.; Zebeli, Q.; Böhm, J.; Mycotoxin Res. 2018, 34, 117.

12. Djinovic-Stojanovic, J. M.; Nikolic, D. M.; Vranic, D. V.; Babic, J. A.; Milijasevic, M. P.; Pezo, L. L.; Jankovic, S. D.; J. Food Compos. Anal. 2017, 59, 50.

13. Cheatham, M. M.; Sangrey, W. F.; White, W. M.; Spectrochim. Acta, Part B 1993, 48, 487.

14. Virgilio, A.; Gonçalves, D. A.; McSweeney, T.; Gomes Neto, J. A.; Nóbrega, J. A.; Donati, G. L.; Anal. Chim. Acta 2017, 982, 31 .

15. Machado, R. C.; Silva, A. B. S.; Donati, G. L.; Nogueira, A. R. A.; J. Anal. At. Spectrom. 2018, 33, 1168.

16. Babos, D. V.; Virgilio, A.; Costa, V. C.; Donati, G. L.; Pereira-Filho, E. R.; J. Anal. At. Spectrom. 2018, 33, 1753.

17. Vieira, A. L.; Kelber, M.; Virgilio, A.; Ferreira, E. C.; Gomes Neto, J. A.; J. Anal. At. Spectrom. 2018, 33, 1354.

18. MacLachlan, D. J.; Budd, K.; Connolly, J.; Derrick, J.; Penrose, L.; Tobin, T.; J. Food Compos. Anal. 2016, 50, 97.

19. Domaradzki, P.; Florek, M.; Staszowska, A.; Litwińczuk, Z.; Biol. Trace Elem. Res. 2016, 171, 328.

Submitted: January 30, 2019 Published online: July 23, 2019 